\title{
Erratum to: Golli Myelin Basic Proteins Modulate Voltage-Operated Ca++ Influx and Development in Cortical and Hippocampal Neurons
}

\author{
V. T. Cheli ${ }^{1}$ • D. A. Santiago González ${ }^{1} \cdot$ V. Spreuer $^{1} \cdot$ V. Handley $^{2}$ - A. T. Campagnoni ${ }^{2}$. \\ P. M. Paez ${ }^{1}$
}

Published online: 4 November 2016

(C) Springer Science+Business Media New York 2016

Erratum to: Mol Neurobiol (2016) Vol 53(8):5749-5771

DOI 10.1007/s12035-015-9499-1

The original version of this article unfortunately contained mistakes on the names of authors. The given names and family names were switched.

The corrected list is presented above and hereby published.

The online version of the original article can be found at http://dx.doi.org/ 10.1007/s12035-015-9499-1.

P. M. Paez

ppaez@buffalo.edu

1 Hunter James Kelly Research Institute, Department of Pharmacology and Toxicology, School of Medicine and Biomedical Sciences, SUNY, University at Buffalo, NYS Center of Excellence, 701 Ellicott, St., Buffalo, NY 14203, USA

2 Semel Institute for Neuroscience and Human Behavior, Intellectual and Developmental Disabilities Research Center, David Geffen, School of Medicine, UCLA, Neuroscience Research Building, 635 Charles Young Drive, Los Angeles, CA 90095, USA 